\title{
Analitik Hiyerarşi Süreci Kullanılarak Coğrafi Bilgi Sistemleri Ortamında Sel ve Taşkın Alanlarının Belirlenmesi: Çanakkale- Karamenderes Havzası Örneği
}

\author{
Ayça $\operatorname{Ertan}^{1}$, Emre Özelkan ${ }^{1,2 *}$, Muhittin Karaman ${ }^{3}$ \\ ${ }^{1}$ Çanakkale Onsekiz Mart Üniversitesi, Lisansüstü Eğitim Enstitüsü, Doğal Afetlerin Risk Yönetimi Anabilim Dalı, Çanakkale, Türkiye, \\ ayca.ertan@outlook.com \\ ${ }^{2}$ Çanakkale Onsekiz Mart Üniversitesi, Mimarlık ve Tasarım Fakültesi, Şehir ve Bölge Planlama Bölümü,17020, Çanakkale, Türkiye, \\ emreozelkan@comu.edu.tr \\ ${ }^{3}$ İstanbul Teknik Üniversitesi, Maden Fakültesi, Jeoloji Mühendisliği Bölümü, 34469 İstanbul, Türkiye, mkaraman@itu.edu.tr
}

Özet

Meteorolojik kökenli bir doğal afet olan sel ve taşkına tam olarak hazırlıklı olmak, klasik mücadele yöntemlerinin Coğrafi Bilgi Sistemleri (CBS) ile oluşturulacak duyarlılık haritalarına göre uygulanması ile mümkün olabilir. Bu çalışmada Çanakkale İl sınırları içerisinde bulunan Karamenderes Havzasının sel ve taşkın analizi CBS ortamında gerçekleştirilmiştir. Sel ve taşkın risk alanların belirlenmesinde çok kriterli karar verme yöntemlerinden (ÇKKVY) Analitik Hiyerarşi Süreci (AHS) kullanılmıştır. AHS içerisinde veri seti olarak litoloji, yağış, eğim, bakı, yükseklik, akarsu ağına uzaklık, arazi kullanımı ve örtüsü (AKÖ) kullanılmıştır. Çalışma alanının ayrıntılı AKÖ haritası Sentinel 2-A uydu görüntülerinin destek vektör makinaları (DVM) denetimli sınıflandırma yöntemi ile sınıflandırılması ile oluşturmuştur. AHS'de kullanılan veri setlerinin sel ve taşkın olayına etki dereceleri AHS yönteminin bir parçası olan ikili karşılaşıtırma ile belirlenmiştir. CBS ortamına aktarılan verilere AHS uygulanarak sel ve taşkın risk haritaları oluşturulmuştur. Geçmiş dönemlerde olan sel ve taşkın olayları doğrulama amaçlı kullanılmıştır ve CBS ortamında AHS kullanılarak bu çalışmada üretilen risk haritaları afet yönetimi sürecinin hazırlıklı olma safhasında kullanılabilirdir.

Anahtar Kelimeler: Sel ve Taşkın, CBS, AHS, Risk Haritası.

\section{Determination of Flood Areas in Geographic Information Systems Platform Using Analytical Hierarchy Process: A case study in Çanakkale - Karamenderes Basin}

\begin{abstract}
Being fully prepared for flood and overflow, which is a natural disaster of meteorological origin, can only be possible by applying classical struggle methods according to the sensitivity maps to be created using Geographic Information Systems (GIS). In this study, flood and overflow susceptibility maps of Kara Menderes Basin, located within the borders of Çanakkale Province, were created in GIS environment. The Analytical Hierarchy Process (AHP), one of the multi-criteria decision-making methods (MCDM), was used to determine the flood and flood risk areas. In the AHP, lithology, precipitation, slope, aspect, elevation, distance to the river network, land use and cover (LULC) were used. The detailed LULC map of the study area was created by classification of Sentinel 2-A satellite images by support vector machines (SVM) supervised classification method. The degree of impact of the datasets used in the AHP on the flood event was determined by pairwise comparison that is the part of AHP method. Flood and overflow risk maps were created by applying AHP to the data set transferred to the GIS environment. Flood and overflow events in the previous periods were used for verification purposes and the risk maps produced in this study using AHP in the GIS environment can be used in the preparedness phase of the disaster management process.
\end{abstract}

Keywords: Flood and overflow, GIS, AHP, Risk Map.

\section{Giriş}

Sel ve taşkınlar, küresel ısınma ve iklim değişikliği neticesinde daha sık yaşanan ve çok ciddi hasarlar veren meteorolojik kökenli bir doğal afettir (Tiryaki ve Karaca, 2018). Kentleşme gibi nedenlerle bitki örtüsünün tahribatı ve toprak kaybı, doğal yapı yerine beton ve asfalt gibi geçirimsiz yüzeylerin alması, atıkların yağmur suyu tahliye sistemlerini tıkaması ve akarsuların doğal akışına müdahaleler sel ve taşkınların şiddetini artıran beşeri etkenlerdendir (Kadıŏlu, 2008; Özdemir, 2008; Demirel 2018). Sel ve taşkınlara karşı geliştirilen klasik mücadele yöntemleri arasında; risk taşıyan bölgelerin önceden belirlenmesi ve bu alanlara taşkın önleme ve kontrol yapılarının yapılması, gerekli alanlarda alt üst sel geçitlerin yapılması, dere yataklarından kontrolsüz aşırı malzeme alımlarının önlenmesi, akarsu yataklarının doğal dengesinin korunması, yerleşim yerlerindeki yağmur suyu tahliye sistemlerinin temizliğinin düzenli yapılması, dere

* İlgili yazar: Çanakkale Onsekiz Mart Üniversitesi, Lisansüstü Eğitim Enstitüsü, Doğal Afetlerin Risk Yönetimi Anabilim Dalı, Çanakkale, Türkiye, emreozelkan@comu.edu.tr 
yataklarının ıslah edilmesi vb. bulunmaktadır (Uşkay ve Aksu, 2002). Klasik mücadele yöntemlerinin doğru uygulanabilmesi için ilk ve en önemli adım taşkın risk haritalarının hazırlanmasıdır (Yılmaz ve ark., 2017). Taşkın risk haritalarının hazırlanmasında CBS tabanlı modeller ve mekânsal analizler günümüzde en çok tercih edilen yöntemlerdendir.

CBS, coğrafi verilerin bilgisayar ortamında depolanması, işlenmesi, analiz edilmesi, güncellenmesi ve görüntülenmesini sağlayan işlemleri içermektedir (Albut, 2012; Chang, 2017). CBS afet yönetiminde afet öncesi hazırlık ve sonrasında yapılacak olan müdahale, iyileştirme ve zarar azaltma çalışmalarında sıklıkla kullanılmaktadır (Arca, 2012; Gigovic vd., 2017). Geniş alanları tek seferde görüntüleme kabiliyeti olan uzaktan algılama (UA) ise afet sonrası arazi örtüsü değişimlerinin belirlenmesi, zamansal değişim analizi, hasar tespiti gibi çalışmalarda kullanılmaktadır (Chan, 1997; Yomralıŏlu, 2000; Genç vd., 2008a; Genç vd., 2008b, Arca, 2012; İnalpulat vd., 2018). UA afet yönetiminde, afetin etkili olabileceği veya olduğu bölgenin fiziki durumu hakkında hızlı ve en güncel verilerin elde edilmesini sağlaması bakımından son derece önemlidir (Batur ve Maktav,2012). CBS'nin etkin kullanımında en önemli unsur veridir, bu bağlamda uzaktan algılamanın gelişmiş bir veri toplama aracı olması nedeni ile CBS ile birlikte kullanımı tercih edilmektedir (Maliene, Grigonis, Palevicius, Griffiths, 2011).

Çok Kriterli Karar Verme Yöntemleri (ÇKKVY) bir konu hakkında karar verme sürecini etkileyen parametreler arasında seçim, derecelendirme, sınıflandırma gibi uygulamalarda kullanılmaktadır (Uludağ ve Doğan., 2016). ÇKKVY bulanık mantık temelli ya da klasik olmak üzere iki temel sınıfta ele alınabilir (Uludağ ve Doğan., 2016). Uygulama alanına göre değişiklik göstermekle birlikte en sık kullanılan ÇKKVY; AHP (Analytical hierarchy process), ANP (Analytical Network Process), MAUT (Multi attribute utility theory), PROMETHEE (The preference ranking organization method for enrichment evaluation), ELECTRE (ELimination and Choice Expressing REality Enrichment), TOPSIS (Technique for Order of Preference by Similarity to Ideal) olarak sıralanabilir (Ishizaka ve Nemery, 2013; Yıldırım ve Önder, 2014; Uludağ ve Doğan, 2016). Matematiksel işlemler ve anlaşılabilirlik açısından diğer yöntemlere kıyasla daha kolay olan AHS, bir problemi ana hedef ve birden fazla kriter ile hiyerarşik bir sistem içerisinde çözümleyen modelleme yöntemidir (Malczewski, 1999; Tokgözlü, Özkan, 2018). Ayrıca AHS ile elde edilen ağırlık değerleri CBS'de kolaylıkla uygulanabilmektedir. Literatürdeki çalışmalar incelendiğinde CBS'de gerçekleştirilen sel ve taşkın risk alanlarının belirlenmesi çalışmalarında en çok tercih edilen parametreler litoloji (El- Magd vd, 2020; Hammami vd ,2019), yağış (Kabenge vd., 2017; Zelenakova vd.,2018;), eğim (El Magd vd., 2020; Ogato vd., 2020), bak1 (Mind'je vd., 2019; Tiryaki ve Karaca, 2018), yükseklik (Tanrıverdi, 2019; Selçuk vd., 2016), akarsu ağına uzaklık (Hoque vd., 2019; Romdani vd., 2018), arazi kullanımı ve örtüsü (AKÖ) (Msabi ve Makonya, 2021; Hammami vd., 2019) olarak sıralanabilir.

Bu çalışmanın amacı, Çanakkale ili sınırlarında bulunan Karamenderes havzası için CBS tabanlı sel ve taşkın risk haritalarının oluşturulmasıdır. Bu bağlamda sel ve taşkın alanlarının belirlenmesinde ÇKKVY'den AHS kullanılmıştır. Çalışmada sel ve taşkın risk alanlarının belirlenmesi için kullanılan parametreler litoloji, yağış, eğim, bakı, yükseklik, akarsu ağına uzaklık, AKÖ olarak seçilmiştir. Seçilen veri setindeki her bir faktörün etki derecesi AHS'de ikili karşılaştırma ile belirlenmiştir. CBS ortamında parametreler çakıştırılarak sel ve taşkın risk haritaları oluşturulmuştur. Çalışmada oluşturulan risk haritalarının doğrulaması geçmiş dönemde yaşanılan taşkınlarla yapılmıştır. Son olarak sel ve taşkınlara dair tespitler ve öneriler sunulmuştur.

\section{2. Çalışma Alanı, Veri ve Yöntem}

Çalışma alanı Çanakkale ili Karamenderes Havzası olup $26^{\circ} 11^{\prime} 39.68^{\prime \prime}$ - 26³5'06.43" doğu meridyenleri ve $40^{\circ} 00^{\prime} 05.72^{\prime \prime}$ - 39॰48'26.44" kuzey paralelleri arasında yer almaktadır (Şekil 1). Çanakkale Merkez ilçenin güneybatı kısımlarını, Bayramiç ve Ezine ilçelerinin büyük bir bölümünü ve Ayvacık ilçesinin kuzey kısımlarını kapsayan Karamenderes Havzası 1991 km²'lik bir alanı kaplamaktadır. Havza güneydoğusunda yüksek ve eğimli alanlar içermektedir ve genel anlamda az eğimli ve çok yüksek olmayan bir araziye sahiptir (Karaman vd., 2018). Havzanın \%39,8'lik kısmı tarım alanlarından oluşmaktadır (Çetinkaya ve Sümer, 2013; Akbulak vd., 2010). Havza içerisinde yer alan baraj ve göletler sırasıyla; Bayramiç Barajı, Akçin, Arasanlı, Örenli, Şapköy, Yeniköy ve Yassıbağ göletleridir (DSİ, 2018).

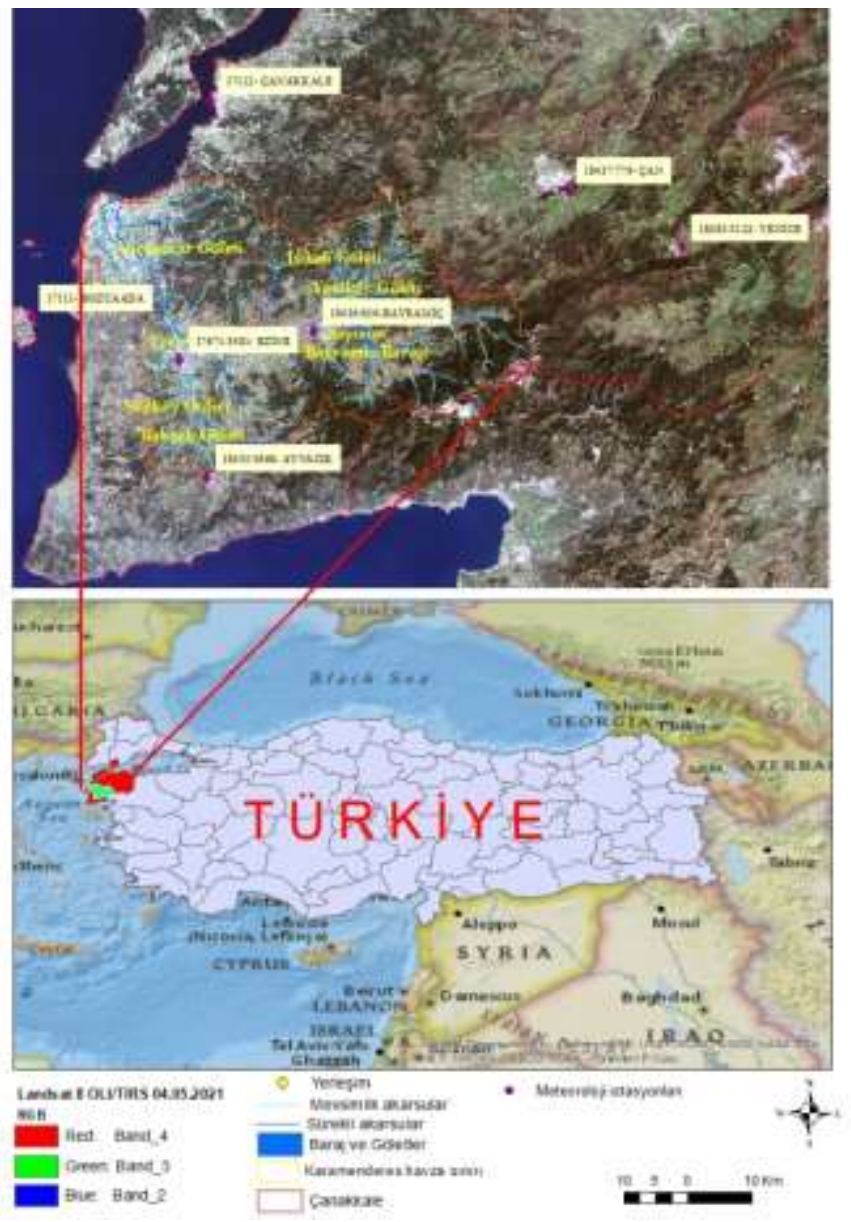

Şekil 1. Çalışma alanı - Karamenderes Havzası.

Meteoroloji Genel Müdürlüğü verilerine göre çalışma alanında en sicak ay $23,6{ }^{\circ} \mathrm{C}$ ile Temmuz, en soğuk ay $5,2{ }^{\circ} \mathrm{C}$ ile Ocak iken yıllık ortalama sıcaklık $14{ }^{\circ} \mathrm{C}$ 'dir. Havzada yıllık ortalama yağış miktarı $624,3 \mathrm{~mm}$ iken en yağışlı ay $118,2 \mathrm{~mm}$ ile Aralık, en az yağışlı ay 8,3 mm ile Ağustos'tur.

Çalışma alanında Karadeniz ikliminden Akdeniz iklimine bir geçiş iklimi olarak ifade edilen bölgesel Marmara İklimi yaşanmaktadır (Şensoy ve ark. 2008; Karaman ve ark. 2018). Karamenderes Havzası'nda farklı tarihlerde taşkın olayları 
gözlenmiștir. Karamenderes Havzasında meydana gelen bazı taşkın olaylarının tarihleri ve meydana geldikleri dereler Tablo 1'de verilmiştir. Bu çalışmada havzada meydana gelen taşkınlardan Ocak 2016, Temmuz 2017 ve Şubat 2018 incelenmiştir.

\subsection{Meteorolojik Veri ve Yağış Haritalarının Olușturulması}

Karamenderes Havzası'na ait günlük toplam yağış, aylık toplam yağış, aylık ortalama sıcaklık, günlük ortalama sıcaklık ve günlük maksimum rüzgâr yönü ve hızı verileri T.C. Orman ve $\mathrm{Su}$ Isşler Bakanlığı Meteoroloji Genel Müdürlüğü'nden (MGM) temin edilmiştir. $\mathrm{Bu}$ çalışmada kullanılan 7 meteoroloji istasyonu (Bayramiç, Ezine, Ayvacık, Çanakkale, Bozcaada, Yenice, Çan) havzayı kapatacak şekilde seçilmiş olup konum bilgileri Tablo 2'de belirtilmiştir. YağıŞ dağılım analizi için mekânsal enterpolasyon yöntemlerinden deterministik bir yaklaşım olan radyal tabanlı fonksiyon (RBF) yöntemi kullanılmıştır. RBF için girdi verileri taşkın dönemlerine ait aylık toplam yağış verileri olup tarihleri sirasiyla Ocak 2016, Temmuz 2017 ve Şubat 2018'dir.

\subsection{Topoğrafik Veri ve işlenmesi}

Harita Genel Komutanlığı (HGK)'ndan temin edilen $1 / 25000$ ölçekli topografik haritaların $10 \mathrm{~m}$ 'de bir sayısallaştırılmış eşyükselti eğrilerinden üretilen $10 \mathrm{~m}$ mekânsal çözünürlüğe sahip verilerinden Karamenderes Havzasına ait sayısal yükseklik modeli (SYM) üretilmiştir. SYM kullanılarak bölgenin topoğrafik özellikleri (eğim, bakı, yükseklik) ve akarsuya uzaklık haritaları CBS ortamında oluşturulmuştur. Ayrıca Karamenderes Havzasının drenaj ağı, akış yönleri, akış birikimi, alt havza sınırlarının ve akarsu havza sınırının oluşturulmasında SYM kullanılmıştır. SYM'den drenaj ağının çıkarılmasında, SYM'deki hatalardan kaynaklı ani düden oluşumu gibi hatalara neden olabilecek noktalarının iyileştirilmesi amacıyla, SYM'deki rastgele boşluk hataları giderilmiştir. Boşluk hatalarının giderildiği SYM'den havza için raster tabanlı hücresel akış yönleri belirlenmiş, devamında akış yönlerinin girdi verisi olarak kullanıldığı hücresel akış birikimi hesaplanmıștır. Havzadaki drenaj ağında ana ve alt akım kolları, hücresel akış birikim verilerinden türetilerek akış sıralaması uygulaması ile akış ağındaki tüm bağlantılara sayısal bir sıra atanmıştır. Akarsu ağı oluşturulduktan sonra akarsuların etrafinda çoklu halka tampon analizi ile oluşturulan tampon bölgelerin, literatürdeki çalışmalarda farklılık gösterdiği görülmektedir (Tokgözlü ve Özkan, 2018; Franci ve ark, 2016; Hoque ve ark, 2019; Rahmati ve ark, 2015). Bu duruma çalışılan alanın parametreler iklim, hidrojeoloji, topografya ve AKÖ özelliklerine göre değişmektedir.

\subsection{Jeolojik Veriler ve İşlenmesi}

Karamenderes Havzası'nda yer alan litolojik birimlerin geçirimlilik durumlarına göre hidrojeolojik özelliklerinin tanımlanmasında ve geçirimlilik haritası oluşturmasında kullanılmak üzere Maden Tetkik ve Arama Genel Müdürlüğü'nden (MTA) elde edilen 1/100.000 ölçekli vektör jeoloji haritasının I16, I17, H16 ve H17 paftaları kullanılmıştır.

\subsection{Uzaktan Algllama Verisi ve Ön İşlemesi}

Çalışmada; AKÖ haritasının oluşturulmasında 17 Nisan 2020 tarihli Sentinel-2A uydu görüntüsü kullanılmıştır. Avrupa Uzay Ajansı'dan (ESA) temin edilen Sentinel-2A multi-spektral uydu görüntüleri 10,20 ve 60 metre mekânsal çözünürlüğe sahip 13 farklı banttan oluşur (ESA, 2013). Sentinel-2A uydu görüntüsünün özellikleri Tablo 3'te verilmiştir. Sentinel 2-A seviye görüntüsünün, $20 \mathrm{~m}$ çözünürlüğe sahip kırmızı kenar ve Kısa dalga kızılötesi (SWIR) ve $60 \mathrm{~m}$ çözünürlüklü 3 atmosferik bandının mekânsal çözünürlüğünün 10 m'ye yükseltilmesi için füzyon yöntemi uygulanmıştır. Numerik yöntemlerden NNDiffuse (Nearest Neighbor Diffusion Based Pansharpening) pankeskinleştirme yöntemi görüntü füzyonunda uygulanmıştır. Sentinel-2A uydu görüntülerinin geometrik düzeltmeleri görüntü sağlayıcı olan ESA tarafından yapılmaktadır (Özelkan vd., 2018).

Tablo 1. Çanakkale Karamenderes Havzasında meydana gelen bazı taşkın olayları

\begin{tabular}{ccc}
\hline $\begin{array}{c}\text { Sel ve Taşkın } \\
\text { Tarihi }\end{array}$ & Akarsu Adı & Erişim Adresi \\
\hline $\mathbf{1 0 . 0 2 . 2 0 1 0}$ & Atikhisar Baraji ve Bayramiç Baraj1 & www.canakkaleicinde.com/atikhisar-ve-bayramic-barajlari-tasti/ \\
$\mathbf{2 7 . 0 2 . 2 0 1 0}$ & Göveren Deresi & www.dunyabulteni.net/arsiv/canakkalede-sel-taskinlari-h106599.html \\
$\mathbf{1 2 . 0 3 . 2 0 1 2}$ & Çamlik Deresi ve Kursak Çayı & www.comuhaber.com/2012/12/03/yagmur-yagdi-canakkalede-hayat-felc-oldu/ \\
$\mathbf{0 2 . 1 2 . 2 0 1 2}$ & Karamenderes Çay1 & www.halkinhabercisi.com/canakkaleyi-sel-ve-lodos-vurdu \\
$\mathbf{1 9 . 0 1 . 2 0 1 3}$ & Tabaklar Deresi & www.mynet.com/bayramici-yaz-yagmuru-vurdu-3386870-myvideo \\
$\mathbf{0 8 . 0 8 . 2 0 1 5}$ & Karamenderes Çay1 & www.sondakika.com/haber/haber-kazdaglari-ndan-inen-sel-sulari-taskina-neden-oldu-8071738/ \\
$\mathbf{1 7 . 0 1 . 2 0 1 6}$ & Karamenderes Çay1 & https://canakkalegundem.net/2017/07/18/canakkale-yagmura-teslim-oldu-2/ \\
$\mathbf{1 8 . 0 7 . 2 0 1 7}$ & Akçin Çayı & www.yeniasir.com.tr/ege/canakkale/2018/02/28/ezinede-sel-felaketi \\
$\mathbf{2 8 . 0 2 . 2 0 1 8}$ & Koçeli Köyü & www.trthaber.com/haber/turkiye/canakkalede-saganak-bazi-ev-ve-is-yerlerini-su-basti-552775.html \\
$\mathbf{0 2 . 0 2 . 2 0 2 1}$ & Bayramiç &
\end{tabular}

Tablo 2. Kullanılan meteoroloji istasyonları ve konum bilgileri

\begin{tabular}{|c|c|c|c|c|}
\hline İstasyon No & İstasyon Adı & Enlem & Boylam & Rakım (m) \\
\hline $18436-626$ & Bayramiç & 39,8147 & 26,5906 & 92 \\
\hline 17671-3481 & Ezine & 39,7739 & 26,3456 & 73 \\
\hline $18435-3668$ & Ayvacık & 39,6081 & 26,3958 & 431 \\
\hline 17112 & Çanakkale & 40,141 & 26,3993 & 6 \\
\hline 17111 & Bozcaada & 39,8326 & 26,0728 & 30 \\
\hline $18085-3122$ & Yenice & 39,9344 & 27,2661 & 252 \\
\hline 18437-779 & Çan & 40,0161 & 27,0564 & 139 \\
\hline
\end{tabular}


Tablo 3. Sentinel-2A uydu görüntüsünün özellikleri

\begin{tabular}{|cccc}
\hline Bantlar & Merkezi Dalga Boyu (nm) & Bant Genişliği (nm) & Mekânsal Çözünürlük (m) \\
\hline Bant 1- Mavi- Aerosol tespiti & 443 & 20 & 60 \\
Bant 2 - Mavi & 490 & 65 & 10 \\
Bant 3 - Yeşil & 560 & 35 & 10 \\
\hline Bant 4 - Kırmızı & 665 & 30 & 10 \\
\hline Bant 5 - NIR - Bitki Örtüsü Sinıflandırması & 705 & 15 & 20 \\
\hline Bant 6 - NIR - Bitki Örtüsü Sinıflandırması & 740 & 15 & 20 \\
\hline Bant 7 - NIR - Bitki Örtüsü Sinıflandırması & 783 & 20 & 20 \\
\hline Bant 8 - NIR & 842 & 115 & 10 \\
\hline Bant 8A - NIR - Bitki Örtüsü Sınıflandırması & 865 & 20 & 20 \\
\hline Bant 9 - NIR - SWIR - Su Buharı & 945 & 20 & 60 \\
\hline Bant 10 - SWIR - Sirüs & 1375 & 30 & 60 \\
\hline Bant 11 - SWIR - Kar/Buz/Bulut Ayrımı & 1610 & 90 & 20 \\
\hline Bant 12 - SWIR - Kar/Buz/Bulut Ayrımı & 2190 & 180 & 20 \\
\hline
\end{tabular}

Ayrıntılı AKÖ, 17 Nisan 2020 tarihli Sentinel 2A uydu görüntüsü kullanılarak piksel tabanlı sınıflandırma yöntemlerinden Destek Vektör Makinaları kontrollü sınıflandırma tekniği ile oluşturulmuştur. Çalışma alanı su, tarım alanı, orman, çayır-çimen, boş arazi, yapay alanlar ve toprak yol olmak üzere toplam 7 sınıfa ayrılmıştır. Sınıflandırma görüntüsünün doğruluğunda kullanılacak 210 adet yer kontrol noktası yüksek çözünürlüklü uydu görüntülerinden rastgele oluşturulmuştur. AKÖ’ye ait sınıflandırmanın doğruluğu sırasıyla Kappa katsayısı ve genel doğruluk istatistiksel metrikleri ile değerlendirilmiştir. Sınıflandırmaya ait genel doğruluk \%90, Kappa katsayısı $0,88^{\prime}$ tir.

\subsection{Yöntem}

ÇKKV yöntemlerinden AHS ile CBS ortamında sel ve taşkın risk haritalarının oluşturulduğu bu çalışmadaki iş akış diyagramı Şekil 2'de verilen aşağıdaki adımlar uygulanmıştır;

1. Uzaktan algilama verilerini düzenleme.

2. AKÖ haritasının oluşturulması.

3. AKÖ haritasının doğruluk analizlerinin yapılması.

4. SYM'den topografik özelliklerin çıkarılması.

5. Sym'den drenaj ağının çıkarılması ve tampon analizi.

6. Yağışın haritalarının oluşturulması.

7. AHS modelinin oluşturulması.

8. Sel ve Taşkın Haritalarının üretimi.

9. Doğruluk analizinin yapılması.

\subsubsection{Kriterlerin Değerlendirilmesi}

ÇKKVY ile Sel ve taşkın alanlarının belirlenmesi için (AHS) (Armacost ve Hosseini, 1994) veri seti bileşenleri; yağış, litoloji, eğim, bakı, yükseklik, akarsu ağına uzaklık, AKÖ seçilmiştir. Seçilen veri setlerinin etki dereceleri AHS'de ikili karşılaştırma ile belirlenmiş ve her faktör CBS ortaminda sayısallaştırılmıştır.

CBS ortaminda sayısallaştırılan değerler çakıştırılarak taşkın risk haritası ortaya çıkarılmıştır.

$\mathrm{Bu}$ çalışmada Karamenderes havzasına ait sel ve taşkın duyarlılık haritasının oluşturulmasında ele alınan parametrelerin ağırlıkları uzman görüşü kullanılmayıp geçmiş dönem sel ve taşkın olayları ve literatür araştırmaları sonucunda belirlenmiştir. AHS de ikili karşılaştırma ile belirlenen ağırlık değerleri her faktör için CBS ortamında öznitelik veri tabanına işlenmiştir.

Sel ve taşkınların meteorolojik kökenli doğal afetler olması sebebi ile meteorolojik parametreler sel ve taşkınların oluşumuna sebep olan doğal faktörlerin başında yer almaktadır (Özşahin, 2013; Hoque ve ark., 2019). İklim değişikliğiyle beraber mevsim geçişlerindeki ani basınç değişimleri, havanın büyük kütle hareketleri, sıcak soğuk havanın çarpıştı̆̆ 1 durumlar, nemli havanın büyük değerlere ulaştığı durumlar yağış rejiminde düzensizliğe neden olur (Kabenge vd., 2017; Zelenakova vd.,2018; Hammami vd., 2019; Oğuz vd., 2016; Özkan ve Tarhan, 2012; Tokgözlü ve Özkan, 2018; Toprak, 2015; Yahaya vd., 2010; Hu vd., 2017 Sel ve taşkınlarda diğer parametreler nispeten sabit olsa da yağış değişkendir. Çalışmada sel ve taşkınların gerçekleştiği ayların aylık toplam yağış verileri kullanılmıştır

Eğim, sel ve taşkın oluşumunda, su birikimi ve akışı bakımından önemli faktörlerin başında gelmektedir (Tanrıverdi, 2019). Su birikimi, düz ve düze yakın alanlarda daha yüksek olduğu için bu alanlar eğim faktörü içerisinde en yüksek riskli grup olarak sınıflandırılır (Ogato vd., 2020). Bu çalışmada eğim değerleri ve aralıkları literatür incelemeleri (El Magd vd., 2020; Ogato vd., 2020; Tanrıverdi, 2019; Tiryaki ve Karaca, 2018; Özşahin, 2013; Özkan ve Tarhan, 2012; Fernandez ve Lutz, 2010) dikkate alınarak belirlenmiştir. Eğim derecelendirme, çok düşük riskten çok yüksek riske kadar beş sınıfa ayrılmıştır ve oluşturulan eğim haritası 0-3, 3-10, 10-25, 25-50, >50 aralıklarını içermektedir. 
Journal of Research in Atmospheric Science

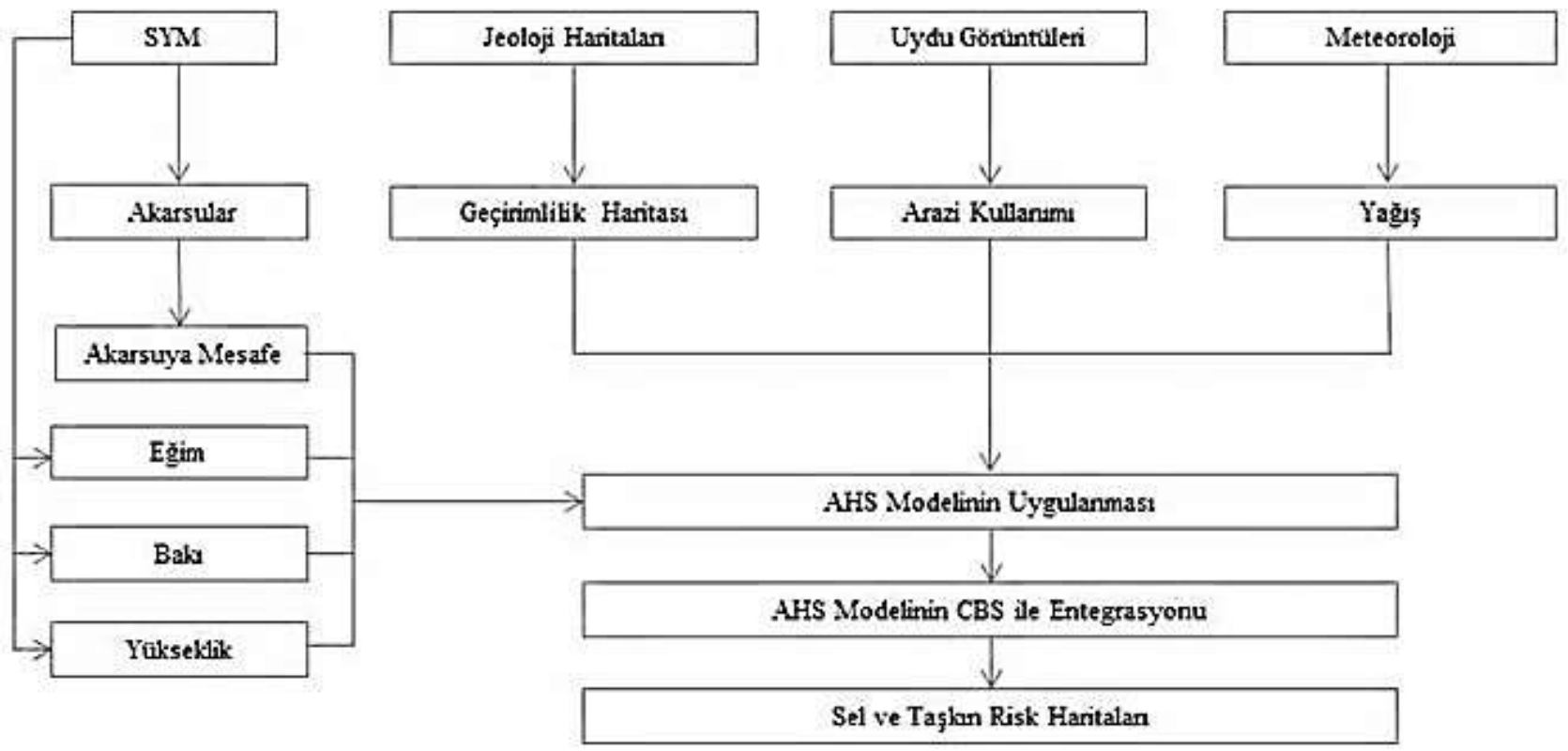

Şekil 2. Çalışmada kullanılan veri, yöntem ve işlem basamakları.

Bakı, güneşten alınan 1S1 enerjisi miktarını etkilemesi sebebi ile buharlaşma, yoğuşma, tutulan veya kaybolan su miktarını etkiler (Tiryaki ve Karaca, 2018). Bunun yanı sıra güneye bakan yamaçlarda evapotranspirasyon oranının fazla olması sebebiyle bitki örtüsü daha seyrektir (Oğuz vd., 2016). $\mathrm{Bu}$ nedenle güneye bakan kısımlarda yüzeysel akış daha fazladır. Ek olarak düz ve düze yakın olan yerler eriyen kar suları ve yağmur sularının birikmesi nedeniyle sel ve taşkın afeti bakımından daha riskli kabul edilmektedir (Dölek, 2015). Çalışmada bakı faktörü düz ve düze yakın alanlar, doğu-batı, kuzeyli bakılar ve güneyli bakılar olmak üzere 4 sinıfta incelenmiştir (Mind'je vd., 2019; Tiryaki ve Karaca, 2018; Yılmaz vd., 2017; Oğuz vd., 2016; Toprak, 2015; Dölek, 2013; Özşahin, 2013; Akar ve Maktav, 2008).

Yükseklik yağış̧ların belli bir alanda toplanması üzerinde önemli etkiye sahip bir parametredir (Rahmati vd., 2015; Görcelioğlu, 2003). Çalışma içerisinde yükseklik değerleri ve aralıkları literatür incelemeleri (Tanrıverdi, 2019; Selçuk vd., 2016; Rahmati vd., 2015; Ogato vd., 2020; Msabi ve Makonyo., 2021) dikkate alınarak 0-161, 161-319, 319-536, 536-899 ve 899-1767 metre olacak şekilde sınıflandırılmıştır.

Sel ve taşkınlardan etkilenecek alanların belirlenmesinde akarsulara uzaklık faktörü kritik rol oynamaktadır (Rahmati vd., 2016). Literatüre göre (Hoque vd., 2019; Romdani vd., 2018; Tokgözlü ve Özkan, 2018; Kabange vd., 2017; Franci vd., 2016; Rahmati vd., 2016; Selçuk vd., 2016) sel ve taşkınlardan en fazla etkilenecek alanlar akarsulara yakın olan alanlardır. Çalışmada kullanılan akarsulara uzaklık haritası $250,500,1000,1500$ ve 2000 metre aralıklarını içermektedir. Bununla birlikte sıvılar yüksek basınçtan alçak basınca doğru hareket eder düşük basınç olan alanlara gelince akış hızı artar bu nedenle akarsu kollarının birleştiği yerlerde birden fazla kol aynı akımda birleştiği için sel ve taşkın riski artar (Dernek, 2012).

AKÖ, suyun yüzeyel akışı bakımından sel ve taşkın oluşumunu dolaylı olarak etkiler (Tanrıverdi, 2019). Bina ve asfaltlanmış alan gibi yapay alanlar suyun yer altına sızma kapasitesini önemli ölçüde etkileyeceği için sel ve taşkınlar bakımından bu alanlar daha riskli kabul edilmektedir (Hammami vd., 2019). Ormanlık alanlarda ağaçlar yapısal olarak toprakta kanallar açar ve yağışlar bu boşluklara nüfus ederek akiferlerde birikir bunun sonucunda yağışların belli bir miktarı yeraltı suyuna karıştı̆̆ için akışa geçen su miktarı azalır bu durum sel ve taşkınlar açısından riski düşürür (Önsoy, 2008). Tarım bitkileri ise kökleri toprağın üst tabakasında ve zayıf olduğu için sel ve taşkınlar açısından daha risklidir kaynak. Çalışmada AKÖ, su, tarım alanı, orman, çayır-çimen, boş arazi, yapay alanlar ve toprak yol olmak üzere toplam 7 sınıfta incelenmiştir (Msabi ve Makonya, 2021; Hammami vd., 2019; Lintang ve Pandianga, 2019; Tanrıverdi, 2019; Tokgözlü ve Özkan, 2018; Franci vd., 2016; Özşahin, 2013).

Litoloji yüzeysel akışı etkilemesi sebebi ile sel ve taşkınların oluşumunda dolaylı bir etkiye sahiptir (Selçuk vd., 2016). Çalışmada bölgeye ait jeolojik birimler, jeoloji raporları kullanılarak geçirimlilik durumuna göre, geçirimli, yarı geçirimli, çok az geçirimli ve geçirimsiz olmak üzere 4 sınıfta incelenmiştir.

\subsubsection{Analitik Hiyerarşi Süreci}

Sel ve taşkın alanlarının belirlenmesi aşamasında kullanacağımız yöntem ÇKKVY'den biri olan 1968 yılında Myers ve Alpet tarafindan ortaya konulan ve Saaty tarafindan 1977 yılında karar verme problemleri için uygulanabilir hale getirilen Analitik Hiyerarşi Sürecidir (AHS) (Armacost ve Hosseini, 1994). Bu modelleme yöntemi pratik kolaylı̆̆ı, yorumlayıcı yaklaşımı ve kolay uygulaması ile birçok karar verme alanında uygulanabilir (Saaty, 1988; Tanrıverdi, 2019).

İlk aşamada değerlendirme kriterleri ve alternatifler belirlenir diğer bir deyişle karar noktaları ve karar noktalarını etkileyen faktörler belirlenir (Yaralıoğlu, 2001).

İkinci aşama olan karşılaştırmada, alt düzeydeki verilerin ilk veri ile ikili karşılaş̧ırmasının yapılabilmesi için bir matris oluşturulur (Saaty, 2000). İkili karşılaştırmalar yapilırken, Tablo 4'de görülen ve Saaty tarafindan önerilen ikili karşılaştırma ölçeği kullanılır. AHS'de çoklu ikili karşılaş̧ırmalar, dokuz seviyeli standartlaştırılmış bir karşılaştırma ölçeğine dayanmaktadır (Saaty, 1997).

Üçüncü aşamada normalize edilmiş matris karar matrisindeki her bir sütun değerinin ayrı ayrı ilgili sütun toplamına bölünmesi ile elde edilir (Dağdeviren vd., 2004). 


\section{Journal of Research in Atmospheric Science}

Dördüncü aşamada normalize edilmiş matristeki her bir satırın aritmetik ortalaması alınarak öncelik vektörü (w) elde edilir (Ustasüleyman ve Perçin, 2007).

Beşinci aşama olan tutarlılık testleri aşamasında amaç karar vericinin ikili karşılaştırma matrisini oluştururken tutarlı olup olmadığının belirlenmesidir (Ömürbek ve Şimşek, 2014). Hesaplama sonucu 0,10'dan küçük ise karş1laştırma matrisi tutarlıdır (Dağdeviren vd., 2004). Tutarlılık hesaplamaları için formül (1) uygulanır (Shi ve Zhou, 2009)

Uyum oranı $(C R)=\frac{C I(\text { uyum indeksi })}{R I \text { (rastgele indeks })}$

RI değeri kriter sayısına göre değişmektedir ve değerleri Tablo 5'te gösterilmektedir (Karagiannidis vd., 2010). Son aşama olan sentez aşamasında ise tüme varım ile öncelikler belirlenir (Saat., 2000).

\section{Bulgular ve Tartışma}

\subsection{Kriter Katmanlart}

Çalışmanın bu bölümünde sel ve taşkın riskine neden olan parametrelerinden litoloji, akarsuya mesafe, AKÖ, eğim, yükseklik ve bakının tematik haritaları Şekil 3'te gösterilmiştir. Ayrıca incelenen taşkın dönemlerine ait yağış dağılım haritaları Şekil 4’te verilmiştir.
Litolojik birimlerin geçirimlilik durumuna göre CBS ortamında hazırlanan haritada çalışma alanının, \%34,88'i çok az geçirimli, \%32,78'i yarı geçirimli \%22,94'ü geçirimli ve $\% 9,4$ 'ü geçirimsizdir. Oransal dağılımı verilen sınıfların Tablo 6'da havzadaki alansal dağılımı verilmiştir.

Akarsuya mesafe ve buna bağlı risk sınıflaması bölgenin iklim, hidrojeoloji, topografya ve AKÖ özellikleri ve geçmişteki sel ve taşkınlar olaylar dikkate alınarak 250, 500, 1000, 1500, 2000 m olarak sınıflandırılmıştır.

AKÖ haritasına göre çalışma sahasının en geniş alanı $\% 44,59$ ile ormanlık alanlardır. AKÖ'nün ikinci grubu \%21,50 ile çayır çimen alanlarıdır. Üçüncü ve taşkın riski açısından en yüksek riske sahip arazi sınıfı \%20,68 ile tarım arazileridir. Çalışma alanının \%9,61'i boş arazidir. Çalışma alanının geriye kalan sinıfları sırasıyla, yapay alanlar \%2,64 su $\% 0,49$ ve toprak alanlar \%0,49'dur. Oransal dağılımı verilen sınıfların Tablo 7'de havzadaki alansal dağılımı verilmiştir.

Topografik özellikler (eğim, bakı, yükseklik) SYM kullanılarak CBS ortamında bir dizi işlem ile çıkarılmıştır. Çalışma sahasında 0-3º eğimli alanlar \%19,62 (39183,65 ha), $3,1-10^{\circ}$ eğimli alanlar \%34,43 (68750,61 ha), 10,1-20 eğimli alanlar \%29,10 (58116,33 ha), 20,1-30 eğimli alanlar \%13,10 (26160,47 ha) ve $30,1-57,6^{\circ}$ eğimli alanlar \%3,74'lük (7478,11 ha) alansal dağılım göstermektedir.

Tablo 4. AHS hiyerarşi tablosu (Saatly., T.L., 1977; Tokgözlü., Özkan., 2018)

\begin{tabular}{cc}
\hline Önem değerleri & Değer tanımları \\
\hline $\mathbf{1}$ & İki faktörün eşit öneme sahip olması durumu \\
$\mathbf{3}$ & 1. Faktörün 2. Faktörden daha önemli olması durumu \\
$\mathbf{5}$ & 1. Faktörün 2. Faktörden çok önemli olması durumu \\
$\mathbf{9}$ & 1. Faktörün 2. Faktörden çok güçlü bir öneme sahip olması durumu \\
$\mathbf{2 , 4 , 6 , 8}$ & 1. Faktörün 2. Faktöre göre mutlak üstün olmasi durumu \\
\hline
\end{tabular}

Tablo 5.RI değerleri (Ömürbek ve Şimşek, 2014)

\begin{tabular}{cccccccccccccccc}
\hline $\mathbf{n}$ & $\mathbf{1}$ & $\mathbf{2}$ & $\mathbf{3}$ & $\mathbf{4}$ & $\mathbf{5}$ & $\mathbf{6}$ & $\mathbf{7}$ & $\mathbf{8}$ & $\mathbf{9}$ & $\mathbf{1 0}$ & $\mathbf{1 1}$ & $\mathbf{1 2}$ & $\mathbf{1 3}$ & $\mathbf{1 4}$ & $\mathbf{1 5}$ \\
\hline $\mathbf{R I}$ & 0 & 0 & 0.58 & 0.90 & 1.12 & 1.24 & 1.32 & 1.41 & 1.45 & 1.49 & 1.51 & 1.53 & 1.56 & 1.57 & 1.59
\end{tabular}

Tablo 6. Litolojik birimlerin geçirimlilik durumuna göre havzadaki alansal dă̆ılımı.

\begin{tabular}{cc}
\hline Litolojik birimlerin geçirimlilik durumu & Havzadaki alansal dağılım (ha) \\
\hline Geçirimli & 45909,60 \\
Geçirimsiz & 18806,84 \\
Yarı geçirimli & 65596,83 \\
Çok az geçirimli & 69793,18 \\
\hline
\end{tabular}

Tablo 7. AKÖ sınıflarının havzadaki alansal dağılımı.

\begin{tabular}{ccc}
\hline AKÖ sınıfları & AKÖ sınıfları havzadaki alansal dağılımı & 89296,52 \\
\hline Orman & 43055,67 \\
Çayır çimen & 41402,44 \\
Tarım alanları & 19236 \\
Boş arazi & 5291,02 \\
Yapay alanlar & 988,27 \\
Su & 981,69 \\
\hline
\end{tabular}

Tablo 8. Taşkın dönemi aylık toplam yă̆ış verileri

\begin{tabular}{|c|c|c|c|c|c|c|c|}
\hline $\begin{array}{c}\text { İstasyon No ve } \\
\text { Adı: }\end{array}$ & $\begin{array}{c}\text { 18436/62 } \\
\text { 6Bayramiç }\end{array}$ & $\begin{array}{c}18437 / 779 \\
\text { Çan } \\
\end{array}$ & $\begin{array}{c}18435 / 3668 \\
\text { Ayvacık }\end{array}$ & $\begin{array}{c}17112 \\
\text { Çanakkale }\end{array}$ & $\begin{array}{c}17111 \\
\text { Bozcaada }\end{array}$ & $\begin{array}{c}\text { 17671/3481 } \\
\text { Ezine }\end{array}$ & $\begin{array}{c}18085 / 3122 \\
\text { Yenice }\end{array}$ \\
\hline Ocak 2016 & $97,4 \mathrm{~mm}$ & $108 \mathrm{~mm}$ & $123,5 \mathrm{~mm}$ & $110,2 \mathrm{~mm}$ & $64,2 \mathrm{~mm}$ & $73,4 \mathrm{~mm}$ & $140,3 \mathrm{~mm}$ \\
\hline Temmuz 2017 & $207,7 \mathrm{~mm}$ & $46,9 \mathrm{~mm}$ & $59,6 \mathrm{~mm}$ & $17,2 \mathrm{~mm}$ & $17,2 \mathrm{~mm}$ & $106,2 \mathrm{~mm}$ & $38,1 \mathrm{~mm}$ \\
\hline Şubat 2018 & $122,3 \mathrm{~mm}$ & $118,3 \mathrm{~mm}$ & $160,3 \mathrm{~mm}$ & $133,5 \mathrm{~mm}$ & $31,8 \mathrm{~mm}$ & $132 \mathrm{~mm}$ & $102,8 \mathrm{~mm}$ \\
\hline
\end{tabular}




\section{Journal of Research in Atmospheric Science}

Çalıșmada 0-161 m yükseklikteki alanlar \%33,82, 161$319 \mathrm{~m} \% 31,88,319-536 \mathrm{~m} \% 23,73,536-899 \mathrm{~m} \% 7,34$ ve 899 $1746 \mathrm{~m} \% 3,23$ oransal dağılım göstermektedir. Buna göre çalışma sahasının en risksiz sınıfı (899-1746 m) 6450,791 ha, en riskli sınıfi (0-161) 67547,6 ha alan kaplamaktadır. Havzanın batı ve kuzeybatısı yükselti bakımından doğu bölgesine göre daha düşük yüksekliğe sahip olduğu için bu bölgelerin sel ve taşkın riski bakımından daha risksiz olduğu görülmektedir.

Yağış dağılım haritalarının oluşturulmasında kullanılan meteoroloji istasyonlarında ölçülen yağış verilerinden elde edilen aylık toplam yağışlar Tablo 8'de belirtilmiştir. Ocak 2016 yağış dağılım haritasına (Şekil 4 (a.)) göre havzanın güney ve güneydoğusunda yağış yoğunluğu fazladır. Temmuz 2017 yağış dağılım haritasına (Şekil 4 (b)) göre havza sınırlarında bulunan Bayramiç ilçesi çevresinde yağış yoğunluğu fazladır.

\subsection{Analitik Hiyerarşsi Süreci'nin Coğrafi Bilgi Sistemlerine Entegresyonu}

Çalışmada veri seti içerisinde her elemana ait ağırlık değerleri geçmiş sel ve taşkınların incelenmesi ve literatür taraması sonucunda belirlenmiştir. Kriter katmanlarının ağırlık değerleri Tablo 9'da verilmiştir. AHS' de yapılan son işlem tutarlılık işlemi olup verilen değerlerin tutarlılığ 0,061'dir. Saaty (1980)'e göre hesaplama sonucu 0,10'dan küçük ise karşılaştırma matrisi tutarlıdır. Bu sonuç çalışmada kullanılan parametrelerin ağırlık değerlerinin tutarlı olduğunu göstermektedir.

\subsection{Sel ve Taşkın Risk Analizi}

Elde edilen verilere göre; Ocak 2016 taşkın döneminde (Şekil 5 (a)) Karamenderes Havzasının \%30,37'si (60209,89 ha) az riskli, \%28,88'i (57244,99 ha) riskli, \%24,03'ü (47643,3 ha) risksiz, \%11,04'ü (21892,9 ha) yüksek riskli ve \%5,67'si (11248,1 ha) çok yüksek riskli bulunmuştur. Meydana gelen taşkında yerel medyadan edilen bilgiye göre, havzanın Güneydoğusunda bulunan Evciler karayolu, Serhat Köyü ve Yassıbağ Köyü arasındaki yol sular altında kalmıştır.

Temmuz 2017 taşkın döneminde (Şekil 5 (b)) Karamenderes havzasının \%39,11'i (77520,41 ha) az riskli, \%27,06's1 (53633,65 ha) riskli, \%21,76's1 (43141,77 ha) risksiz, \%9,67 (19178,58 ha) yüksek riskli ve \%2,40’1 $(4755,258$ ha) çok yüksek riskli bulunmuştur. Yerel medyaya göre, Bayramiç’te meydana gelen yağışlar ilçede sele neden olmuştur.

Şubat 2018 taşkın döneminde (Şekil 5 (c)) Karamenderes Havzasinın \%33,3'ü $(66075,04$ ha) risksiz, \%31,21'i $(61865,59$ ha) az riskli, \%20,60'1 (40845,07 ha) riskli, $\% 11,63$ 'ü (23059,57 ha) yüksek riskli ve \%3,22'si (6384,171 ha) çok yüksek riskli bulunmuştur.

Çalışma sonucunda CBS ortamında üretilen, Çanakkale Karamenderes Havzasının Ocak 2016, Temmuz 2017 ve Şubat 2018 taşkın dönemi risk haritalarının, yerel basına göre taşkın sonucunda sular altında kalan alanlar ile örtüştüğü görülmektedir. Risk haritalarında alansal değişimde baskın olan faktörün yağış olduğu görülmektedir.

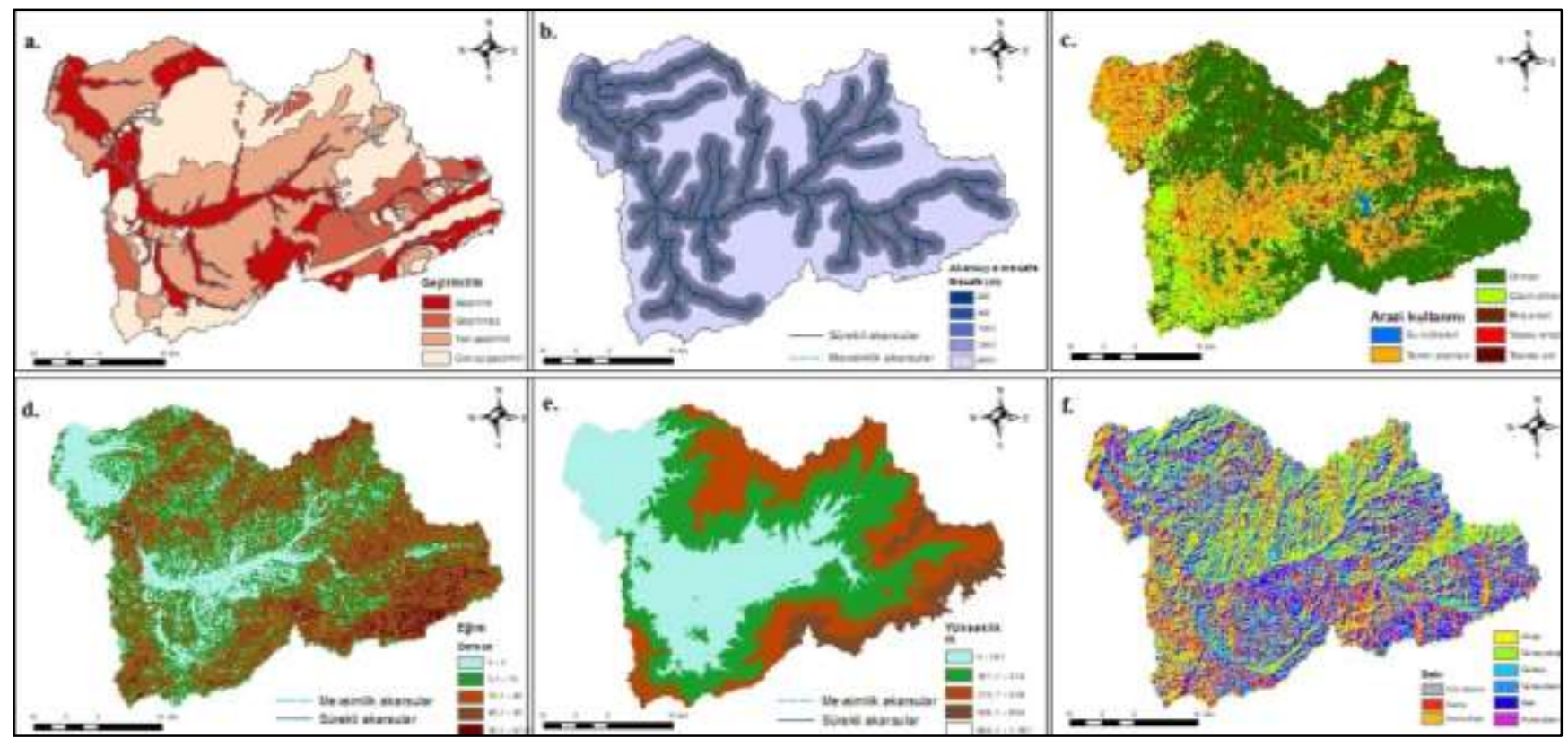

Şekil 3. Sınıflandırılmış kriter katmanları; geçirimlilik (a), akarsuya mesafe (b), AKÖ (c), eğim (d), yükseklik (e), bakı (f) 
Tablo 9. Kriter katmanlarının ă̆ırlık değerleri

\begin{tabular}{|c|c|c|c|c|c|c|c|}
\hline & Yağış & Eğim & AKÖ & Yükseklik & Bakı & Derelere uzaklık & Litoloji \\
\hline Yağıș & 1 & 3 & 5 & 4 & 7 & 2 & 6 \\
\hline Eğim & $1 / 3$ & 1 & 4 & 2 & 5 & $1 / 4$ & 4 \\
\hline AKÖ & $1 / 5$ & $1 / 4$ & 1 & $1 / 3$ & 4 & $1 / 5$ & 2 \\
\hline Yükseklik & $1 / 4$ & $1 / 2$ & 3 & 1 & 4 & $1 / 5$ & 2 \\
\hline Bakı & $1 / 7$ & $1 / 5$ & $1 / 4$ & $1 / 4$ & 1 & $1 / 7$ & $1 / 3$ \\
\hline Akarsulara uzaklık & $1 / 2$ & 4 & 5 & 5 & 7 & 1 & 6 \\
\hline Litoloji & $1 / 6$ & $1 / 4$ & $1 / 2$ & $1 / 2$ & 3 & $1 / 6$ & 1 \\
\hline
\end{tabular}
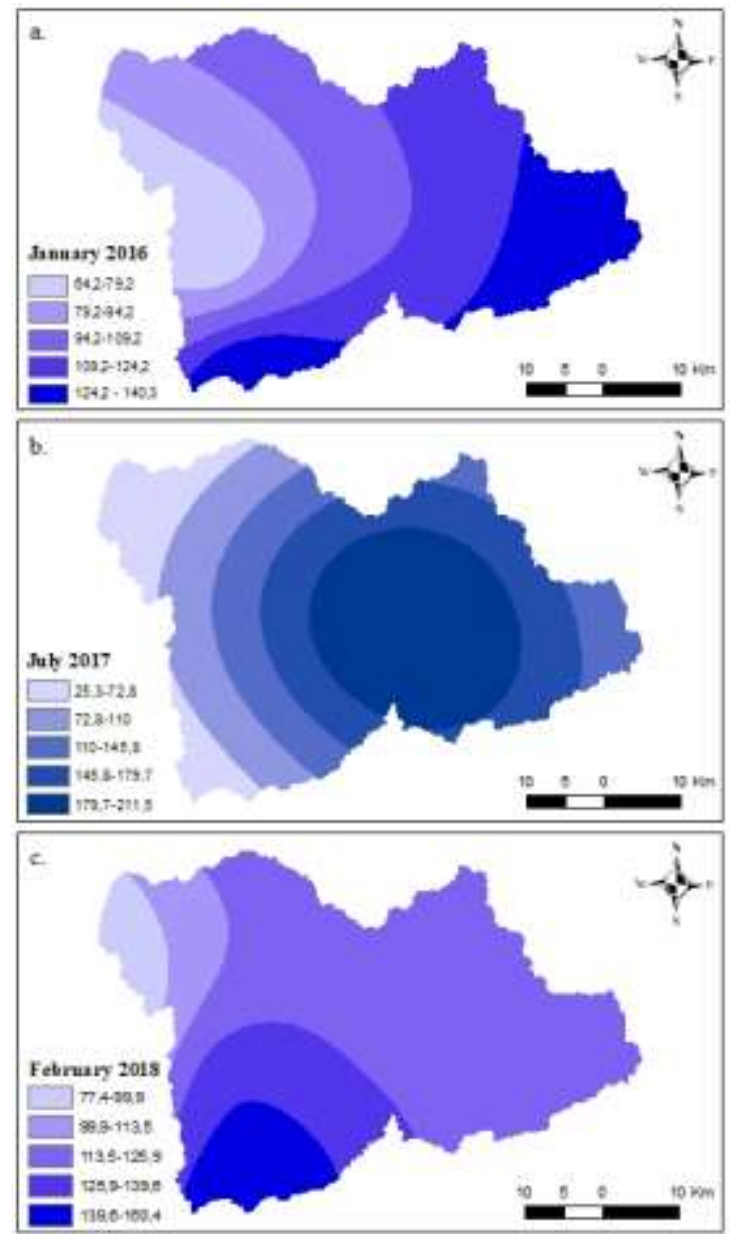

Şekil 4. Ocak 2016 (a), Temmuz 2017 (b) ve Şubat 2018 (c) taşkın dönemlerine ait alansal yağış dağılımı

\section{Sonuç ve Öneriler}

$\mathrm{Bu}$ çalışmada Çanakkale Karamenderes Havzasında meydana gelen taşkınlara ait risk haritaları AHS yöntemi ile CBS ortamında oluşturulmuştur. Çalışma sonucunda, beklenildiği gibi ormanlık alanlar sel ve taşkın riski açısından düşük duyarlılığa sahipken tarım alanları ve yapay alanlar riskli bulunmuştur. İncelenen geçmiş taşkınlarda akarsuların yön değiştirdiği ve akarsu kollarının birleştiği noktaların sel ve taşkın duyarlılığının yüksek olduğu görülmektedir. Yağış rejimindeki değişiklikler sel ve taşkın oluşumunda en belirleyici parametredir. CBS tabanlı sel ve taşkın haritaları geçmiş vakalar dikkate alındığında tutarlıdır. Meteorolojik kökenli doğal afetlerden biri olan sel ve taşkınlar küresel iklim değişikliği, plansız kentleşme ve yetersiz altyapı sebebiyle artış göstermektedir. Bu bağlamda çalışmada oluşturulan sel ve taşkın risk haritalarının afet ve risk yönetimi ve doğal kaynak yönetimi gibi alanlarda yarar sağlayacağı düşünülmektedir.

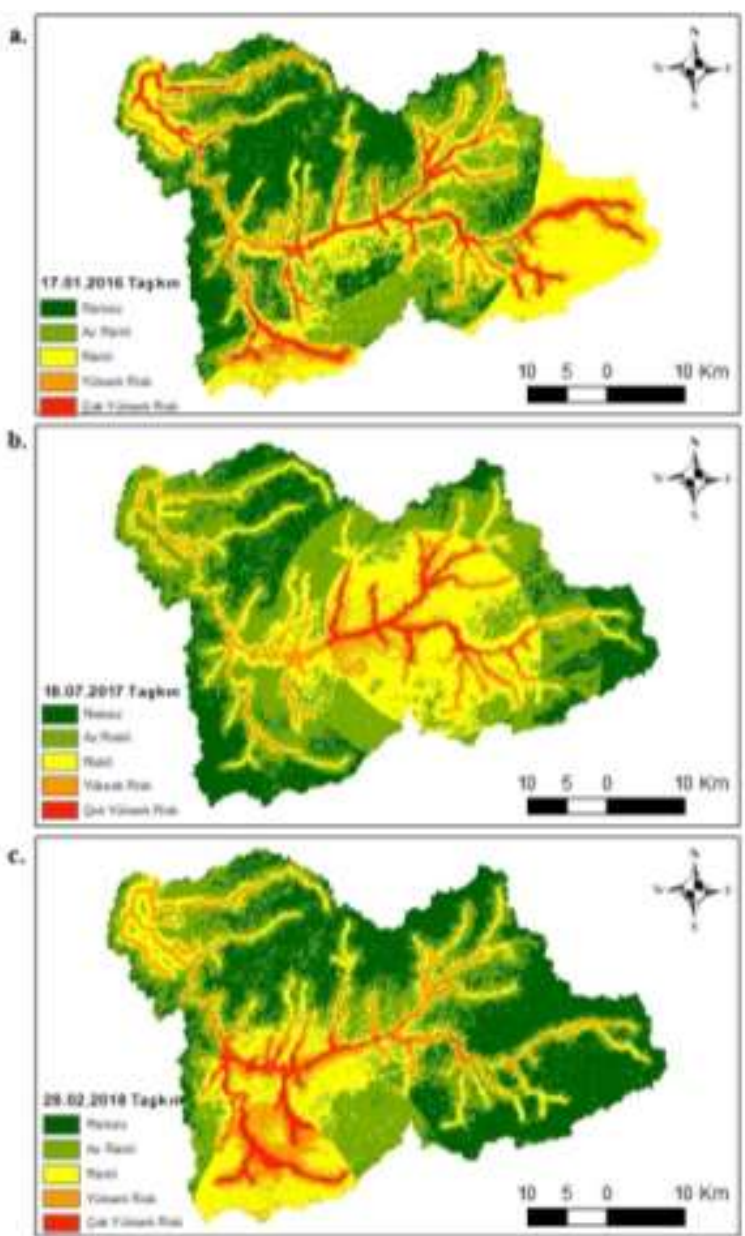

Şekil 5. Ocak 2016 taşkın risk haritası (a), Temmuz 2017 taşkın risk haritası (b), Şubat 2018 taşkın risk haritası (c)

\section{Teşekkür}

Yazarlar Uydu görüntülerinin ve meteorolojik verilerin ve jeolojik verilerin paylaşımından dolayı sırasıyla Avrupa Uzay Ajansı'na (ESA), T.C. Orman ve Su İşleri Bakanlığı Meteoroloji Genel Müdürlüğü'ne ve Maden Tetkik ve Arama Genel Müdürlüğü'ne teşekkür eder. $\mathrm{Bu}$ çalışma Ayça ERTAN'ın Çanakkale Onsekiz Mart Üniversitesi, Lisansüstü Eğitim Enstitüsü, Doğal Afetlerin Risk Yönetimi anabilim dalında yürütülen yüksek lisans tezi kapsamındadır. Bu çalışma Çanakkale Onsekiz Mart Üniversitesi Bilimsel Araştırma Projeleri Koordinasyon Birimince Desteklenmiştir. Proje Numaras1: 3253.

\section{Kaynaklar}

AGI. (1991). GIS Dictionary. Ver. 1.1, Association for Geographical Information Standarts Comittee Publication, UK. 
Akbulak, C. (2010). Analitik hiyerarşi süreci ve coğrafi bilgi sistemleri ile Yukarı Kara Menderes Havzası'nın arazi kullanımı uygunluk analizi. Uluslararası İnsan Bilimleri Dergisi, 7(2), 557-576.

Arca D. (2012). Afet Yönetiminde Coğrafi Bilgi Sistemi ve Uzaktan Algılama. Karaelmas Fen ve Mühendislik Dergisi, 2 (2), 53-61.

Armacost, R. L., \& Hosseini, J. C. (1994). Identification of determinant attributes using the analytic hierarchy process. Journal of the Academy of Marketing Science, 22(4), 383.

Bağdatlı, M.C., Albut, S., 2012. Taşkın Kontrolü Çalışmalarında CBS'nin Kullanım Etkinliğinin Değerlendirilmesi: Tekirdağ Maymun Deresi Havzası Pilot Uygulaması. IV. Uzaktan Algılama ve Coğrafi Bilgi Sistemleri Sempozyumu. 16-19 Ekim 2012. Zonguldak.

Çetinkaya, O., Sümer A. (2013). Karamenderes Havzası Topraklarının Yarayışlı Mikro Besin Elementlerinin (Fe, $\mathrm{Cu}, \mathrm{Zn}$ ve Mn) Durumu, ÇOMÜ Ziraat Fakültesi Dergisi, 2013:1(1), 57-65.

Dağdeviren, M., Akay, D. ve Kurt, M. (2004). İş Değerlendirme Sürecinde Analitik Hiyerarşi Prosesi Ve Uygulamasi. Gazi Üniversitesi Mühendislik-Mimarlık Fakültesi Dergisi, 19(2).

Demirel, K. (2018). Sulama Sistemlerinin Altyap1 Çalışmalarındaki Yeri ve Önemi. Değişen ve Gelişen Lapseki Kentsel Altyapısı, Sağlık A., Editör, Çanakkale Onsekiz Mart Üniversitesi, Çanakkale, ss.45-55.

Dereli, M. A. (2019). Sentinel-2A Uydu Görüntüleri ile Giresun İl Merkezi için Kısa Dönem Arazi Örtüsü Değişiminin Belirlenmesi. Afyon Kocatepe Üniversitesi Fen Ve Mühendislik Bilimleri Dergisi, 19(2), 361-368.

DSİ. (2018). İşletmedeki Tesisler, http://bolge25.dsi.gov.tr/isletmedekitesisler

ESA. (2013). "SENTINEL-2 User Handbook". Paris.

Genç, L., Demirel, K., Çamoğlu, G., Arıcı, İ., Turhan, H., Genç, H., Smith, S. (2008a). 9th International Conferance on Precision Agricultural, Colarada, Amerika Birleşik Devletleri, 20 - 23 Temmuz 2008, ss.129.

Genç, L., Turhan, H., Demirel, K., Çamoğlu, G., Aşar, B., İnalpulat, M. (2008b). Ege Uni. Ziraat Fak. Derg, 45(1), 57-63.

Görcelioğlu, E. (2003). Sel ve çığ kontrolü. İÜ Orman Fakültesi Yayınları, (4415/473,384).

İnalpulat, M., Genç, L., Demirel, K., Kızıl, Ü. (2018). 2nd International Congress on Architecture and Design, 11 12 Ekim 2018.

Kabange, M., Elaru, J., Wang, H., Li, F., (2017). Characterizing flood hazard risk in data-scarce areas, using a remote sensing and GIS-based flood hazard index. Nat Hazards, 89:1369-1387

Karaman, M., Özelkan, E., Taşdelen, S. (2018). Dar Nehirlerin Sentinel 2-A Uydu Görüntüleri ile Belirlenebilirliğinde Havza Hidrojeolojisinin Etkisi: Karamenderes (Çanakkale) Örneği. Doğal Afetler ve Çevre Dergisi, 4(2): 140-155.

Khaleghi, S., \& Mahmoodi, M. (2017). Assessment of flood hazard zonation in a mountainous area based on GIS and analytical hierarchy process. Carpathian Journal of Earth and Environmental Sciences, 12(1), 311-322.

Korkanç, Y.S., Korkanç, M. (2006). Sel ve Taşkınların İnsan Hayatı Üzerindeki Etkileri. ZKÜ Bartın Orman Fakültesi Dergisi 8(9): 42-49.

Kourgialas, N. N. ve Karatzas, G. P. (2011). Flood management and a GIS modelling method to assess flood- hazard areas - a case study. Hydrological Sciences Journal-Journal des Sciences Hydrologiques, 56(2), 212225.

Malczewsk1, J. (1999). GIS and Multicriteria Decision Analysis, John Wiley and Sons, New York.

Maliene, V., Grigonis, V., Palevičius, V., Griffiths, S. (2011). Geographic information system: Old principles with new capabilities. Urban Design International. 16(1), 1-6. (2011). https://doi.org/10.1057/udi.2010.25

Önsoy, H., 2008. Kentleşmede hidrolojinin önemi, 5. Dünya Su Forumu Bölgesel Hazırlık Süreci Türkiye Bölgesel Su Toplantıları: Sel, Taşkın ve Heyelan Konferansları Bildiriler Kitab1, s.38-42.

Özelkan, E., Sağlık, A., Sümer, S. K., Bedir, M., Kelkit, A. (2018). Kentleşmenin Tarım Alanları Üzerine Etkisinin Uzaktan Algılama ile İncelenmesi-Çanakkale Örneği. ÇOMÜ Ziraat Fakültesi Dergisi, 6(1), 123-135.

Rahmati, O., Zeinivand, H., Besharat, M. (2015). Flood Hazard Zoning İn Yasooj Region, Iran, Using GIS And Multi-Criteria Decision Analysis. Geomatics, Natural Hazards and Risk, 7 (3): 1000-1017.

Saaty, T. L. (1997). That is not the analytic hierarchy process: what the AHS is and what it is not. Journal of MultiCriteria Decision Analysis, 6(6), 324-335.

Saaty, T. L. (2000). Fundamentals of decision making and priority theory with the analytic hierarchy process (Vol. 6). RWS publications.

Selçuk, L., Selçuk, A. S., Kasapoğlu, D. (2016). Coğrafi Bilgi Sistemleri (CBS) tabanlı Çok Kriterli Karar Analizi (ÇKKA) kullanılarak, Van ili merkez ilçelerinin kentsel taşkın duyarlılık değerlendirmesi Van/Türkiye. Yerbilimleri Dergisi, 37(1).

Sensoy, S., Demircan, M., Ulupınar, U., Balta, İ. (2008). Türkiye İklimi

Shi, J. ve Zhou, S. (2009). Quality control and improvement for multistage systems: A survey. Iie Transactions. 41(9), 744-753.

Tanrıverdi, M. (2019). Coğrafi Bilgi Sistemleri(Cbs) Tabanlı Çok Ölçütlü Karar Analizi İle Şanlıurfa İl Merkezi’nin Taşkın Alanlarının Belirlenmesi. Harran Üniversitesi Fen Bilimleri Enstitüsü (Yüksek Lisans Tezi), Şanlıurfa.

Tokgözlü A., Özkan E. (2018). Taşkın Risk Haritalarında AHS Yönteminin Uygulanması: Aksu Çayı Havzası Örneği1

Ustasüleyman, T. ve Perçin, S. (2007). Analitik A ğ Süreci Yaklaşımıyla Kuruluş Yeri Seçimi. Gazi Üniversitesi İktisadi ve İdari Bilimler Fakültesi Dergisi, 9(3).

Uşkay S., Aksu S. (2002). Ülkemizde Taşkınlar, Nedenleri, Zararları ve Alınması Gereken Önlemler, TMH- Türkiye Mühendislik Haberleri Say1 420-421-422

Yalçın, M. (2012). Afet Yönetimi-Hazırlık Bileşeni İçin Konumsal Veri Altyapısı Tasarlanması, Sel ve Taşkına Duyarlı Alanlar: İstanbul Avrupa Yakası Örneği. Yıldız Teknik Üniversitesi Fen Bilimleri Enstitüsü Y. Lisans Tezi, İstanbul.

Yılmaz, İ., Öztürk, D., ve Kırbaş, U. (2017) . Çorum İli Taşkın Tehlikesinin Analitik Hiyerarşi Yöntemi Kullanılarak İncelenmesi. (Yüksek Lisans Tezi). Ondokuz Mayıs Üniversitesi, Samsun. 